\title{
CONDICIONES DE IDENTIDAD PARA ORGANISMOS
}

\author{
JosÉ TOMÁs ALVARADO \\ CRISTÓBAL UNWIN
}

\begin{abstract}
. in this work it is proposed that the conditions of identity for biological organisms are given by the following principle: for all organisms $x$ and $y, x=y$ if and only if $x$ has been caused by the self-preserving activity of $y$. This principle determines both the inter-temporal identity of organisms and the identity of organism in different possible worlds. It unifies what can be supposed about conditions of identity coming from - at least - three different conceptions about the nature of biological organisms, those of Robert Wilson, Thomas Pradeu and Ellen Clarke. These conceptions are presented and compared.
\end{abstract}

Keywords: Organisms; individuals; identity in time; biological organisms; biological individuals.

\section{Introducción}

El concepto de 'organismo' tiene una importancia central para las diferentes disciplinas de la ciencia biológica (cf. Pepper y Herron 2008; Clarke 2010, pp.312-5). Aún cuando muchas veces se trate de un supuesto no explicitado, la medicina, la biología del desarrollo, la inmunología, la ecología o la biología molecular parten de la base de que tratan acerca de 'organismos' biológicos que son las entidades que se 'enferman' y cuyas enfermedades provocan respuestas inmunológicas, son las entidades que ocupan diversos roles en los ecosistemas, o son las entidades cuyo desarrollo interesa. Esta importancia es, si cabe, aún mayor en la biología de la evolución. Interesa aquí determinar qué individuos son los más aptos para reproducirse —o para sobrevivir. Pero, ¿qué es reproducirse? ¿Y qué ha de contar como un 'individuo' para estos efectos? La respuesta intuitiva es que los individuos han de ser 'organismos'. Reproducirse es generar otros 'organismos' de la misma 'especie'. Qué se entienda por un organismo habrá de ser fundamental, por lo tanto, para especificar cuándo se ha producido una 'reproducción' y, por lo tanto, qué tan apto sea algo desde una perspectiva evolucionista. Por ejemplo, si uno supone que organismos diferentes deben poseer un genotipo diferente, entonces todo lo que provenga por clonación de un organismo habrá de contar como parte de él. Un bosque de árboles como el Populus tremula debería contar como un gran organismo ocupando una región espacial discontinua (cf. Janzen 1977; Sterelny y Griffiths 1999). Aunque un solo árbol haya generado un bosque completo, este hecho no contaría como reproducción. Ese árbol tendría una fertilidad igual a cero.

Principia 21(1): 13-40 (2017).

Published by NEL — Epistemology and Logic Research Group, Federal University of Santa Catarina (UFSC), Brazil. 
Pero el concepto de 'organismo' no sólo es de relevancia para la ciencia biológica. Parte de la comprensión que tenemos de nosotros mismos es que somos organismos biológicos o, por lo menos, de que estamos compuestos de organismos. Una corriente muy importante en las discusiones acerca de la identidad personal ha sostenido que las condiciones de identidad en el tiempo de una persona son las condiciones de identidad de un mismo organismo (cf. en especial, Olson 1997; 2007, pp.2347; Snowdon 2014). Por supuesto, hay también una larga tradición filosófica que ha resistido esta idea y que ha sostenido, o bien que la identidad de una persona en el tiempo tiene que ver con cierta continuidad psicológica (cf. por ejemplo, Locke, 1975[1690], II, ch.27; Martin y Barresi 2003; Perry 2008), o bien que las personas son sustancias de un carácter no-físico cuya relación con un organismo biológico es accidental (cf. por ejemplo, Swinburne 1984). Tanto las teorías psicológicas como las diferentes formas de dualismo han estado plagadas de problemas. Si no hay claridad acerca de qué sea un organismo y cuáles sean sus condiciones de identidad, sin embargo, es muy difícil que las posiciones que se alejan de estas teorías psicológicas y dualistas puedan contar como alternativas razonables, siquiera inteligibles. Nótese, por lo demás, que si las condiciones de identidad de una persona son las condiciones de identidad de un organismo hay múltiples problemas éticos que van a depender de qué sea exactamente un 'organismo'. Si yo soy idéntico a un organismo biológico, ¿cuándo he comenzado a existir? ¿O en qué momento habré dejado de existir? Cada vez que ese organismo con el que me identifico exista, yo también estaré existiendo. Todo lo que se haga o se deje de hacer a ese organismo se me ha hecho o se me ha dejado de hacer a mí.

En este trabajo se pretende examinar la cuestión de cuáles sean las condiciones de identidad de un organismo para lo que es indispensable entender con más precisión qué sea un organismo. En general, la concepción que se tenga de qué es un $F$ determina cuáles sean las condiciones de identidad de un $F$. En efecto, los hechos acerca de si lo que parecen ser dos entidades son realmente la misma entidad o no, tienen que ver con cuál sea la esencia o naturaleza de tales entidades y, con ello, tienen que ver con lo que podría o no acaecerle a esas entidades. Para lo que sigue, se va a suponer que las condiciones de identidad para un organismo están determinadas por un principio que ha de tener la siguiente forma, expresado en lógica modal cuantificacional de primer orden:

Identidad $\quad \square \forall x \forall y[((x$ es un organismo $) \wedge(y$ es un organismo $)) \rightarrow$ $\square((x=y) \leftrightarrow R x y)]$

Se trata de un principio necesario, pues está determinado por la esencia de un organismo. La identidad entre los organismos $x$ e $y$ ha de estar fundada en el hecho de que $x$ e $y$ se encuentran en la relación $R$. La cuestión que se trata de elucidar 
aquí, por lo tanto, es cuál sea tal relación $R$ de manera de satisfacer el principio de Identidad. Es conveniente hacer algunas observaciones acerca de este principio:

(a) Formalmente, lo que se encuentra en el consecuente del principio de Identidad es un bicondicional. Lo que se pretende, sin embargo, cuando se busca especificar condiciones de identidad de un tipo de entidad es la clarificación de qué sea aquello de lo que dependan ontológicamente tales entidades. Debe entenderse, por lo tanto, que los hechos acerca de qué entidades se encuentran entre sí en la relación $R$ buscada determinan ontológicamente la identidad de esas entidades. No se trata, entonces, de la especificación de algún criterio que nos permita — eventualmente- llegar a saber cuando dos aparentes entidades son la misma entidad. Un principio de identidad no es un criterio epistemológico.

Si uno postula condiciones de identidad para cierto tipo de entidades, uno debe estar sosteniendo que esas entidades no son ontológicamente 'primarias'. Ha de tratarse de entidades dependientes de otras. Esto es de gran importancia para lo que sigue, pues aunque gran parte de nuestros contemporáneos está inclinado a pensar que los organismos biológicos deben estar fundados en hechos más básicos de carácter bioquímico, el fracaso en identificar condiciones de identidad precisas para organismos no debe verse - al menos, no en principio- como un motivo para rechazar la inteligibilidad del concepto de 'organismo'. Puede acaecer que no existan condiciones de identidad para organismos, esto es, que no haya nada en lo que la identidad de un organismo sea dependiente, porque los organismos sean entidades fundamentales.

(b) Formalmente, la relación $R$ que se busca debe ser una relación de equivalencia, esto es, debe ser reflexiva, simétrica y transitiva, pues sólo de ese modo podrían los hechos acerca de tal relación $R$ fundar la identidad de organismos. La identidad es, por supuesto, una relación de equivalencia. Es la 'más pequeña' relación de equivalencia, pues implica toda otra relación de equivalencia. Por ejemplo, es una relación de equivalencia 'tener el mismo tamaño que'. Es reflexiva, pues todo tiene el mismo tamaño que sí mismo. Es simétrica, pues si $x$ tiene el mismo tamaño que $y, y$ debe tener el mismo tamaño que $x$. También es transitiva, pues si $x$ tiene el mismo tamaño que $y$ e $y$ tiene el mismo tamaño que $z$, entonces $x$ debe tener el mismo tamaño que z. Trivialmente, si $x=y$, entonces $x$ tiene el mismo tamaño que $y$. De un modo general, para una relación de equivalencia $S$ cualquiera, vale que $[(x=y) \rightarrow S x y]$. Por lo tanto, si un par de entidades no están en una relación de equivalencia $S$, se sigue - por contraposición- que no son idénticos. Esto permite excluir a priori cualquier candidato para constituir la relación $R$ que no satisfaga alguno de estos requerimientos.

(c) No hay indicaciones especiales en el principio de Identidad acerca del tiempo en que se supone que existen los organismos de que se trate. Tampoco hay restric- 
ciones modales explícitas. Lo que se espera de una especificación de condiciones de identidad es que ponga de manifiesto qué determina la identidad de las entidades en cuestión en el tiempo, así como qué determina la identidad de tales entidades en diferentes 'mundos posibles'. ${ }^{1}$ Si el organismo $x$ en el tiempo $t_{1}$ es idéntico al organismo $y$ en el tiempo posterior $t_{2}$, entonces $x$ persiste temporalmente entre $t_{1}$ y $t_{2}$. Las condiciones de identidad temporales, por lo tanto, especifican las condiciones de persistencia en el tiempo de los organismos. Desde el punto de vista modal, por otro lado, si el organismo $x$ en el mundo posible $w_{1}$ es idéntico al organismo y en el mundo posible $w_{2}$, entonces lo que quiera que acaezca a $y$ es una vicisitud posible para $x$. Las condiciones de identidad modales, por lo tanto, especifican las situaciones contrafácticas que podrían acaecerle a un organismo, esto es, las vicisitudes que podrían acaecerle sin que dejase de ser el organismo que es. En la discusión que se va a efectuar aquí se tratarán tanto las cuestiones temporales como las cuestiones modales.

Hay enormes debates tanto acerca de la identidad en diferentes mundos posibles, como acerca de la persistencia en el tiempo. No se puede desconocer este contexto metafísico general a la hora de considerar la cuestión específica de las condiciones de identidad de un organismo. Algunos filósofos han sostenido, por ejemplo, que ningún objeto existe en más de un único mundo posible (cf. Lewis 1986, pp.210-220). Para estos filósofos las condiciones de verdad de las atribuciones modales a un objeto acerca de lo que podría acaecerle aunque no le ha acaecido de hecho están fijadas por hechos acerca de sus 'contrapartidas', que son objetos numéricamente diferentes en otros mundos posibles aunque suficientemente semejantes. Desde esta perspectiva, la búsqueda de condiciones de identidad modales para organismos es ociosa, pues nada existe en más de un mundo posible y, por lo tanto, nada es idéntico a otro objeto en otro mundo posible. En lo que concierne a la persistencia en el tiempo el cuestionamiento no ha sido menor. Algunos filósofos han sostenido que nada existe más que un único instante puntual de tiempo. Lo que nos parece ser un objeto que existe en varios tiempos, siendo idéntico en todos esos tiempos, es simplemente una fusión mereológica de 'partes temporales' o 'etapas' que existen en cada uno de esos tiempos puntuales (cf. Lewis 1986, pp.202-4; Sider 2001, pp.74-208). Desde esta perspectiva es ocioso pretender hallar condiciones de identidad en el tiempo para organismos, pues nada es idéntico a algo en un tiempo diferente.

Si hemos considerado que vale la pena examinar la cuestión sobre las condiciones de identidad de organismos es porque, por lo menos, estamos inclinados a pensar que estas perspectivas metafísicas más generales están equivocadas. Por supuesto, no podríamos desarrollar aquí los motivos para tal rechazo. La consideración del problema específico de las condiciones de identidad de organismos, sin embargo, puede ofrecer perspectivas frescas sobre el debate general. Para muchos, por ejemplo, una motivación importante para abrazar concepciones en las que la persistencia en el tiempo 
está dada por partes temporales es que parece poco claro cómo es que un mismo objeto puede existir siendo idéntico en distintos tiempos cuando hay variaciones en sus propiedades intrínsecas y en el material de que está constituido (cf. por ejemplo, Sider 2001, pp.140-208). Una explicación adecuada de cómo es que un organismo persiste en el tiempo a pesar de los cambios que sufre - o gracias a esos cambiospuede ayudar a desactivar esas motivaciones y hacer más verosímil el punto de vista tradicional.

\section{Individualidad biológica y organismos: tres teorías}

En lo que sigue, revisaremos tres teorías sobre individualidad biológica y organismos. Todas ellas guardan ciertas similitudes entre sí. Hay, en cada caso, una cierta preocupación por lograr una definición que sea al menos compatible con lo que sabemos hoy sobre los diversos procesos evolutivos por selección natural. En principio, el orden será el siguiente. Primero, expondremos la visión tripartita de Robert Wilson (2005). En segundo lugar, presentaremos las líneas generales de la teoría inmunológica sobre organismos de Thomas Pradeu (2010; 2012; 2013). Por último, daremos cuenta de los puntos principales de la postura que desarrolla Ellen Clarke (2013) en torno a estas cuestiones.

\subsection{Robert Wilson: visión tripartita}

La posición de Robert Wilson (2005) en torno a los organismos biológicos recoge algunas de las preocupaciones que otras perspectivas han mostrado sobre el mismo asunto. Parte de esta recepción apunta, en primer lugar, al papel que cumplen las clases naturales (natural kinds) en la caracterización de lo que es un organismo y, en segundo lugar, a una conexión entre estos últimos y los agentes vivientes. Con estos elementos como base, Wilson (2005) elabora una perspectiva propia y sostiene que un organismo es:

(1) un agente viviente (living agent)

(2) que pertenece a un linaje reproductivo, en el cual algunos miembros tienen el potencial de poseer un ciclo de vida (life cycle) intergeneracional, y

(3) que tiene autonomía (autonomy) funcional mínima (Wilson 2005, p.59).

En líneas generales, la propuesta de Wilson consiste en una visión tripartita de los organismos basada en: (1) la pertenencia de estos a un grupo amplio de entidades (agentes vivientes), (2) una relación con un proceso determinado (ciclos de vida), y (3) la posesión de algún grado de autonomía. Con (1) Wilson establece el dominio que integran los organismos, mientras que con (2) y (3) los distingue de otras 
entidades que también forman parte de (1). A continuación se tratarán de manera secuencial cada una de las piezas que conforman esta visión.

\subsubsection{Agentes vivientes}

Wilson afirma que la categoría de 'agente viviente' corresponde a una clase natural (2005, p.56). La definición de 'agente viviente' involucra dos cuestiones. Primero, aquello que caracteriza, en general, a un agente, a saber, ser una fuente de causación espacialmente delimitada (Wilson 2005, p.50). Segundo, el cúmulo de propiedades que define a la clase:

(a) Tener partes que son heterogéneas y especializadas, incluir una variedad de mecanismos internos, contener diversas moléculas orgánicas, incluyendo ácidos nucleicos y proteínas.

(b) Crecer y desarrollarse, reproducirse, repararse cuando están dañados.

(c) Tener un metabolismo, contar con adaptaciones medioambientales (Wilson 2005, pp.56-7).

Las propiedades de (a), (b) y (c) conforman el cúmulo de propiedades homeostáticas que define a la clase de 'agente viviente'. Las primeras corresponden al tipo de propiedades que configuran las diversas estructuras de los agentes vivientes. Las segundas, en cambio, son propiedades de índole funcional y especifican el tipo de cosas que los agentes pueden hacer en virtud de las propiedades estructurales que poseen. Las últimas, por su parte, abarcan a un amplio grupo de propiedades funcionales que se distinguen de las segundas por el tipo de interacciones que mantienen con el entorno del agente viviente (Wilson 2005, p.58). Así, un organismo, en cuanto miembro de la clase natural 'agente viviente', es una entidad que posee un número suficiente de las propiedades del cúmulo que determina a la clase.

\subsubsection{Ciclos de vida}

Una diferencia fundamental entre organismos y otros agentes vivientes es que los primeros forman parte de linajes reproductivos que cuentan entre sus miembros a entidades capaces de instanciar un ciclo de vida intergeneracional (Wilson 2005, pp.59-62). Un ciclo de vida consiste, a grandes rasgos, en "una sucesión causal de entidades, cada una de ellas un agente viviente, las que junto a los procesos que median la sucesión, vuelven a ocurrir a lo largo de las generaciones" (Wilson 2005, p.60). No se trata, sin embargo, de que todos los eventos de la vida de un organismo sean parte de su ciclo de vida. Se trata, más bien, solo de aquellos eventos que dan muestras de inicio o finalización de un proceso y que se encuentran, además, temporalmente limitados. Ejemplos de esto son la fertilización de un óvulo en mamíferos 
que se reproducen sexualmente y la formación de mitosporas en algunas algas de reproducción asexual. Para Wilson, un organismo es "la entidad paradigmática que tiene o posee un ciclo de vida, y las entidades que conforman este ciclo son etapas en la vida de aquel organismo" (2005, p.60). Así caracterizados, es notorio que los ciclos de vida guardan conexiones estrechas tanto con la reproducción, como con los mecanismos que median la sucesión de etapas, a saber, los procesos de desarrollo.

Wilson, quien sigue en esto a Griesemer (2000), distingue la replicación, como mero proceso de copia, de la reproducción, como un proceso que involucra progeneración y desarrollo (aunque cf. Godfrey-Smith 2009, p.100). La progeneración se caracteriza por la multiplicación de entidades semejantes a través de procesos en los que hay traslapes de elementos materiales entre generaciones. Por su parte, el desarrollo consiste en la disposición para adquirir la capacidad de reproducirse (Wilson 2005, p.60). Esta doble dimensión es precisamente lo que distingue a la reproducción de la replicación: en la primera hay algo más que la sola copia (Wilson 2005, p.60). Distinciones como estas le permiten diferenciar, a su vez, a los organismos, que pueden poseer un ciclo de vida intergeneracional en virtud de su capacidad reproductiva, de otras entidades. Una diferencia entre organismos y, por ejemplo, sus órganos, es que, aun cuando ambos forman linajes, estos últimos son reproducidos en el marco de los ciclos de vida de los primeros, sin ser agentes de reproducción, y sin recorrer procesos de desarrollo que los lleven a adquirir la capacidad de reproducirse. En otros casos la diferencia viene dada porque las distintas etapas del ciclo de vida de un pretendido organismo no son agentes vivientes (como en el caso de pequeñas cadenas de $\mathrm{ADN}$ que, en algún sentido, forman linajes).

Con todo, hay ciertos casos que podrían resultar difíciles de abordar desde esta posición. Por ejemplo, en algunos insectos sociales hay miembros del linaje que no son capaces de reproducirse, puesto que son estériles. Wilson (2005 p.60) resuelve este asunto sosteniendo que un organismo es al menos una realización parcial del ciclo de vida que posee, de modo que no es necesario que durante su propia historia de vida se realice el ciclo completo. En el caso mencionado, basta con que algún miembro del linaje lleve a cabo el ciclo completo para poder afirmar que el resto de los miembros también poseen un ciclo de vida intergeneracional (Wilson 2005, p.71). Esto traslada, en algún sentido, los hechos que hacen de algo un organismo a las propiedades que poseen otros miembros de su linaje (Wilson 2005, p.62). Del mismo modo, aliviana la exigencia reproductiva, al menos en lo que concierne a organismos particulares. Esto es así porque, si bien reproducirse deja de ser un requisito para que un organismo particular posea un ciclo de vida, sigue siendo una condición necesaria, a nivel de linaje, para la configuración de algo así como un ciclo de vida intergeneracional. A modo de síntesis provisoria, un organismo es un agente viviente, poseedor de un ciclo de vida que puede realizar al menos parcialmente, y parte de un linaje reproductivo tal que al menos un miembro del linaje al que pertenece 
lleva a cabo el ciclo de vida intergeneracional de manera completa.

\subsubsection{Autonomía}

Un rasgo distintivo que Wilson atribuye a los organismos, y que recoge, por cierto, parte de nuestras intuiciones cotidianas sobre ellos, es su autonomía. Rescata con este atributo la idea de que los organismos tienen algo así como una vida propia (2005, p.63), es decir, que ejercen algún grado de control sobre ellos mismos, y que son capaces, además, de maniobrar entre las dificultades que les presentan tanto otros agentes vivientes como el resto del medio ambiente en el que viven. De todos modos, la autonomía y el control se dan en grados, y estos varían dependiendo de la propiedad, objeto o entorno con el que se establezca algún tipo de interacción. Así, por ejemplo, algunos organismos pueden tener autonomía relativa con respecto a la regulación de su temperatura en estadios tardíos de desarrollo, o su respiración, o su propio metabolismo, y carecer de ella frente a la determinación del sexo que, como nota Wilson (2005, p.64), en algunos casos responde a variaciones de temperatura en el ambiente de desarrollo inicial. La autonomía de los organismos consiste, en definitiva, en un asunto de control dentro de sus propios límites y libertad relativa frente a todo aquello que se encuentra fuera de estos (2005, p.93). Un organismo es, entonces, un agente viviente que posee un ciclo de vida y cierta autonomía (p.93).

\subsection{Thomas Pradeu: teoría inmunológica}

Thomas Pradeu (2010; 2012; 2013) sostiene que la función provista por el sistema inmune es fundamental para definir la individualidad biológica en el nivel de los organismos multicelulares (2013, p.92). A diferencia de Wilson (2005), Pradeu funda su propuesta sobre un criterio que es, en apariencia, ${ }^{2}$ único: el funcionamiento del sistema inmune. Algunas de las novedades de esta perspectiva no tienen que ver solamente con el empleo de este criterio, sino también con el contenido del mismo. Pradeu (2010) abandona la teoría tradicional sobre respuestas inmunitarias (la teoría del self-nonself) por una teoría de la continuidad (continuity theory). Lo que las distingue, en lo fundamental, es un criterio de inmunogeneidad (immunogenicity), esto es, la identificación de las circunstancias que suscitan una reacción del sistema inmunitario. Los proponentes de la teoría de la continuidad, como el mismo Pradeu, sostienen que las respuestas del sistema inmune son provocadas por patrones moleculares anormales de crecimiento, sin importar si estos son de origen endógeno o exógeno (2010 p.242), que se encuentran en algún grado de interacción con los receptores inmunitarios y no, como suponen quienes defienden la teoría antes mencionada, por la sola presencia de elementos extraños (nonself) al sistema biológico reconocido como propio (self) por el sistema inmune (2012, p.256).

Principia 21(1): 13-40 (2017). 
Antes de exponer en detalle los puntos principales de la posición de Pradeu, será útil revisar algunas definiciones y distinciones preliminares que emplea a lo largo de sus diversas exposiciones. Un individuo es una "entidad que puede ser designada por medio de una referencia demostrativa (este F), es separable, contable, tiene lindes espaciales bien definidos, y exhibe identidad transtemporal, es decir, capacidad para seguir siendo el 'mismo' mientras varía a través del tiempo" (Pradeu 2013, p.79). Esta definición de individuo le permite, de paso, definir a los individuos biológicos como cualquier cosa viviente que pueda satisfacer los requerimientos de individualidad ya señalados (Pradeu 2013, p.79). Una cuestión que distingue a la propuesta de Pradeu de otras (cf. Buss 1987; también, por razones metodológicas, Clarke y Okasha 2013), es que no afirma que la categoría de 'individuo biológico' sea idéntica a la de 'organismo' y, por lo mismo, no utiliza los términos de manera intercambiable. La primera categoría es más amplia que la segunda y, por cierto, incluye a los elementos que componen a esta última (Pradeu 2012, p.249).

\subsubsection{Sistema inmune e individuación}

Una dificultad para la teoría de Pradeu radica precisamente en la identificación del sistema inmune y algunas de sus funciones como mecanismos individuatorios a nivel de organismos. ¿Cuántos organismos - fenomenalmente concebidos, esto es, aquellos que intuitivamente percibimos como tales (Pradeu 2013, p.81) — poseen realmente un sistema inmune? Pradeu piensa que un enfoque centrado exclusivamente en la presencia y actividad de los linfocitos ha llevado a creer, erróneamente, que solo algunos vertebrados poseen sistemas inmunes. Por el contrario, sostiene que "en todos los organismos multicelulares que han sido investigados, se ha encontrado un sistema inmune, entendido como un sistema de interacciones bioquímicas específicas que tienen como consecuencia el rechazo de algunas entidades vivas" (Pradeu 2013, p.81). En una disposición similar, Pradeu sugiere que uno puede hablar de la presencia de un sistema inmune "cada vez que se encuentren interacciones específicas entre receptores y ligandos capaces de llevar a la destrucción (lysis) del objetivo" (2010, p.254). Una caracterización como esta permite situar a los sistemas inmunes tradicionalmente reconocidos como casos particulares de un mecanismo general que se encuentra ampliamente distribuido en variados rincones del mundo natural.

Visto lo anterior, es posible dar cuenta del papel que cumple el sistema inmune en la individuación de organismos. Pradeu sostiene que la inmunidad contribuye a la individuación de los organismos en al menos dos niveles. En primer lugar, la actividad del sistema inmune propicia la individuación fisiológica de los organismos por medio de un proceso recurrente que traza sus respectivos límites (2010, p.92). En segundo lugar, algunas de las actividades de este sistema han contribuido tanto al surgimiento como al mantenimiento de la cohesión (cohesiveness) que caracteriza 
a los organismos (2010, p.92). Se trata, en este último caso, de una individuación evolutiva.

La individuación fisiológica ocurre, en parte, gracias a un principio de inclusión articulado por interacciones regulares, aunque no permanentes, entre el sistema inmune y las reacciones bioquímicas locales que mantienen entre sí algunos elementos, ya sean endógenos o exógenos, con el resto del organismo (Pradeu 2010, p.244). Gran parte de estas interacciones ocurren como resultado de los mecanismos de patrullaje (policing mechanism) que el sistema emplea para mantener a raya a los distintos componentes. Algunas de las interacciones suscitan respuestas que van desde la inclusión —definida como la ausencia de rechazo — de ciertos elementos, hasta "la eliminación de componentes vivos que se reproducen de manera descontrolada" (Pradeu 2013, p.89). Todo esto determina, en definitiva, "cuáles componentes se mantienen unidos y, por lo tanto, son partes de un mismo organismo" (Pradeu 2013, p.79). Esta serie de discriminaciones posibles, que ocurren, por lo demás, cada ciertos intervalos de tiempo, llevan a Pradeu a señalar que la inmunidad nos ofrece también un criterio de inclusión diacrónica, esto es, indica a aquello que hace de algo "una unidad constituida de diferentes entidades a través del tiempo" (2010, p.254).

Un elemento clave de la teoría de Pradeu que ilumina, además, los dos últimos puntos, es que concibe a los organismos en general, y particularmente a los organismos multicelulares, como entidades heterogéneas. Con esto último no alude solo a fenómenos genéticos como el quimerismo o el mosaicismo (por ejemplo, cf. GodfreySmith 2009, pp.75-80), sino también al carácter y origen diverso de las entidades que constituyen, en distintos grados de importancia, a la mayoría de los organismos. Así ocurre, por ejemplo, con las endobacterias que viven en ellos (Pradeu 2013, p.88). El carácter sistémico y específico de los procesos inmunológicos consiste precisamente en la interacción regular - y espacialmente diversificada a lo largo del organismoentre dichos procesos y conjuntos de entidades que incluyen a elementos exógenos de todo tipo (Pradeu 2010, pp.244-7). Lo que asegura la unidad y cohesión de organismos así constituidos es, entonces, la actividad constante del sistema inmune sobre una base de reacciones bioquímicas entre entidades de diversas naturalezas y orígenes.

Al igual que Buss (1987) y Clarke (2013), Pradeu sostiene que la individualidad es algo que ha surgido y ha sido mantenido en el curso de la evolución (2013, p.82). El problema es, como indica el mismo Pradeu, una cuestión de niveles. ¿Cómo es que individuos de un nivel inferior en una cierta jerarquía — como genes, cromosomas o células, según sea el caso- han llegado a constituir individuos de un nivel superior - por ejemplo, organismos_, y cómo se ha mantenido ese nivel de organización? Hay al menos dos mecanismos que pueden contribuir a solventar estos problemas. El primero corresponde a un mecanismo preventivo, o ex ante, que evita el surgimiento de conflictos relativos a la aptitud (fitness) entre los individuos situados en 
el nivel inferior a través de un incremento de la homogeneidad genética del individuo de nivel superior compuesto por estos (Pradeu 2013, p.82). Ejemplos de estos mecanismos son la separación entre células somáticas y germinales (germlines) en etapas tempranas del desarrollo y los cuellos de botella (bottlenecks). Sin embargo, como en algunos casos la prevención no es suficiente, también hay mecanismos ex post que se encargan de eliminar a los individuos de nivel inferior que favorecen su propio éxito reproductivo (Pradeu 2013, p.82). El asunto de fondo es evitar que los niveles inferiores adquieran propiedades que los pongan en la mira de la selección natural, de modo que el conflicto potencial y la competencia entre ellos sea reemplazada por algún grado de cooperación que mantenga, en lo posible, la cohesión del nuevo individuo de nivel superior.

¿Puede el sistema inmune desempeñar alguno de estos papeles? Pradeu sugiere que los mecanismos de patrullaje y eliminación funcionan, en última instancia, como mecanismos ex post. De esta manera, el sistema inmune se presenta como un fragmento de importancia fundamental en lo que toca a la mantención de la individualidad en procesos evolutivos (Pradeu 2013, pp.83-6). Asimismo, la presencia de estos mecanismos, junto a la identificación y eliminación de aquellos componentes que dan muestras de crecimientos descontrolados, resulta relevante no solo para la mantención de la individualidad, sino también para la construcción de esta: "un sistema inmune que elimina componentes anormales es estrictamente necesario para que una colección de células se convierta en un individuo unificado y cohesionado, u 'organismo"' (Pradeu 2013, p.87).

Después de haber revisado lo anterior, es posible introducir la definición que Pradeu propone para los organismos biológicos, en especial para aquellos de carácter multicelular:

Un organismo es un todo funcionalmente integrado, compuesto por componentes heterogéneos que están localmente conectados por interacciones bioquímicas fuertes y controlados por interacciones inmunes que son sistémicas y constantes, de intensidad media constante (2010, p.244; también en 2012, p.258).

Esta definición condensa algunas de las cuestiones ya mencionadas. Resalta, por ejemplo, la naturaleza heterogénea de los organismos, así como también las interacciones bioquímicas e inmunológicas que los configuran. La conclusión de Pradeu es que los organismos son entidades biológicas inmunológicamente individualizadas (2013, p.92). Su teoría nos permite, en primer lugar, dar cuenta de la unidad de los organismos a pesar de su naturaleza heterogénea. Además, da ciertas luces sobre las características que podrían ayudarnos a diferenciar organismos de otros individuos biológicos. Y, por último, sugiere alternativas para comprender de mejor manera algunas transiciones evolutivas (2013).

Principia 21(1): 13-40 (2017). 


\subsection{Ellen Clarke: la múltiple realizabilidad de los individuos biológicos}

Hasta aquí hemos revisado dos intentos por identificar las propiedades que hacen de algo un organismo. No es extraño notar, sin embargo, que entre tales intentos hay diferencias. La pregunta es si acaso es posible conciliar estas y otras alternativas. Ellen Clarke (2013) cree que es posible si se atiende, en primer lugar, a los problemas que estas pretenden resolver y, en segundo lugar, a las funciones que desempeñan las propiedades que articulan a cada una de las propuestas. Clarke nos ofrece una definición de individualidad biológica basada en la posesión de mecanismos capaces de desempeñar funciones que resultan, a la larga, necesarias tanto para la configuración como la mantención de un organismo en el marco de la evolución por selección natural (2013, p.413). Con esto último recoge, por cierto, parte de las preocupaciones que muestran también Pradeu (2013), Wilson (2005) y otros. Se trata de dar cuenta de la naturaleza de los organismos desde una perspectiva que no solo sea informativa con respecto al estado actual de estos, sino también en lo que concierne a su origen en las transiciones y trayectorias evolutivas a las que se han visto expuestos (Clarke 2013, p.413).

Clarke sostiene que algo es un organismo "sólo si posee mecanismos que le proporcionan las propiedades necesarias para participar en un proceso de selección, esto es, la capacidad de variación heredable de aptitud (heritable variance in fitness)" (2013, p.430). En otras palabras, las propiedades relevantes para la identificación de algo así como un organismo son las mismas que determinan la extensión o la eficacia con la que puede participar de un proceso de selección natural (Clarke 2013, p.427). ${ }^{3}$ El núcleo de la propuesta de Clarke consiste, primero, en la identificación de ciertas funciones capaces de estructurar a una entidad tal que ésta pueda participar de un proceso selectivo y, luego, en la búsqueda de múltiples mecanismos que en los hechos son capaces de realizar, en diversos grados, estas funciones. Las funciones son dos: patrullaje (policing) y demarcación (demarcation).

Un mecanismo de patrullaje "es aquel que inhibe la capacidad de un objeto para experimentar selección entre sus partes" (Clarke 2013, p.421). Pensar este asunto en términos de entidades colectivas y niveles dentro de una jerarquía ayuda a aclarar el asunto. En un individuo biológico pueden convivir entidades distribuidas en distintos niveles. Podemos, por ejemplo, situar al organismo en el nivel $x$, en el $x-1$ a las células, y así sucesivamente. La mayoría de los niveles puede, en circunstancias determinadas, adquirir las propiedades necesarias para desencadenar un proceso de selección natural. Lo que hace el mecanismo de patrullaje es despojar - ya sea previniendo o suprimiendo- al nivel $x-1$ de estas propiedades a fin de evitar la disrupción del nivel $x$ que las entidades del nivel $x-1$ componen. La función del mecanismo es salvaguardar la estabilidad del nivel $x$. Posturas aparentemente disímiles con respecto a qué hace de algo un organismo —o un individuo biológico, según 
corresponda - han coincidido en la importancia de esta función, pero no así en los mecanismos capaces de realizarla. Ya hemos visto en el sistema inmune un mecanismo particular capaz de cumplir con este papel (Pradeu, 2013), pero hay muchísimos otros. Algunos han propuesto a los cuellos de botella reproductivos (bottlenecks), a la división de labores reproductivas (germlines) o, incluso, a la homogeneidad genética como propiedades fundamentales para la individuación biológica (para observar las consecuencias de esta última posición, cf. Janzen, 1977). En el fondo, todas ellas son mecanismos que intentan solucionar el mismo problema: el conflicto selectivo entre componentes (Clarke 2013, p.419). La primera tesis de Clarke es que un organismo, para poder ser tal, debe necesariamente poseer algún mecanismo capaz de realizar la función de patrullaje.

Sin embargo, esta sola función no es suficiente. Y no lo es puesto que el papel que cumple es puramente negativo; no dice nada, por ejemplo, acerca de las capacidades del nivel $x$ para participar de un proceso selectivo (Clarke 2013, p.423). Y esto último, como ya vimos, es una condición necesaria para que algo sea un organismo. Los mecanismos de demarcación cumplen con esta función. Clarke los define como "cualquier mecanismo que incrementa o mantiene la capacidad de un objeto para experimentar procesos de selección entre objetos" (2013, p.424). Los mecanismos de patrullaje antes mencionados establecen relaciones entre entidades de nivel $x \mathrm{y}$ otras de nivel $x-1$ que las componen. En cambio, los mecanismos de demarcación establecen relaciones entre entidades distintas que se encuentran en un mismo nivel de jerarquía. Es importante notar, sin embargo, que no se trata de mecanismos escindidos. En efecto, Clarke señala que ambos están relacionados:

Los mecanismos de demarcación en el nivel $x-1$ contrarrestarán a los mecanismos de patrullaje en el nivel $x$. En general, el patrullaje en $x$ reduce la variación de aptitud (fitness) dentro de las unidades de nivel $x$, mientras que la demarcación en $x$ incrementa la selección entre unidades de nivel $x$ (2013, p.425).

Así como ocurría con los mecanismos de patrullaje, también los mecanismos de demarcación convergen en una función común. Se trata ahora de acentuar o mantener las capacidades de un objeto para participar de procesos selectivos, cuestión estrechamente ligada a las diferencias evolutivamente relevantes que hay entre las entidades biológicas que participan de ellos. La reproducción sexual, por ejemplo, a través de la recombinación, "crea entidades que son todas distintas unas de otras [...] añade variación heredable a la población y por medio de ello incrementa la capacidad de aquella población para evolucionar por selección natural" (Clarke 2013, p.424). Otros han centrado sus propuestas en los límites físicos entre objetos como mecanismos de demarcación, pues mantienen las diferencias heredadas (Clarke 2013, p.425). También hay quienes han señalado al sistema inmune y sus respuestas como fuentes 
de demarcación, en especial cuando estas evitan que un organismo sea absorbido por otros (Clarke 2013, p.425). Cada uno de estos mecanismos mejora, con distintos grados de efectividad, las probabilidades de que haya selección entre objetos.

En ambos casos se trata de mecanismos individuatorios. Clarke los define como mecanismos tales que "o bien limitan la capacidad de un objeto para experimentar selección entre sus componentes (tipo patrullaje) o bien incrementan su capacidad para participar de procesos de selección entre objetos (tipo demarcación)" (2013, p.427). Lo que hacen es sentar las bases para que un organismo, o individuo biológico, según sea el caso, pueda exhibir variación heredable de aptitud (Clarke 2013, p.429). De esta manera, los organismos individuales quedan definidos por la posesión de dichos mecanismos, sin necesidad de que posean realizaciones específicas de ellos; cualquiera que sea capaz de realizar la función, sin importar el grado en que lo haga, satisface el requerimiento (p.429). En cuanto a la reconciliación de posturas mencionada en un comienzo, consiste en haber notado que tales teorías identificaban "mecanismos posibles que satisfacen una labor funcional necesaria" (p.429).

\section{Condiciones de identidad para organismos}

Existen diferencias importantes entre estas posiciones acerca de la naturaleza de un organismo biológico, pero también hay importantes puntos de coincidencia. Estos puntos de coincidencia son especialmente notorios cuando se trata de las concepciones de Pradeu y Clarke. En ambos casos la idea central es que la operación de ciertos sistemas - el sistema inmunológico en el caso de Pradeu y los sistemas de 'patrullaje' y 'demarcación' en el caso de Clarke- es lo que funda la identidad del organismo. En vez de pensar que un organismo es algo ya dado con contornos precisos, o relativamente precisos respecto de su ambiente que debe ser 'preservado' y 'protegido' por el sistema inmune, éste sirve, al menos en parte, para fijar los contornos que diferencian el organismo respecto de su ambiente. Clarke generaliza la perspectiva de Pradeu en dos sentidos. En primer lugar, no sólo el sistema inmune, sino también otros mecanismos tienen una función de limitar o controlar el surgimiento de formas de competencia entre las partes que conforman un organismo. Todos ellos pueden ser agrupados como formas de realizar la función de 'patrullaje'. En segundo lugar, no sólo contribuyen a determinar la identidad del organismo las funciones que limitan o impiden el surgimiento de competencia entre los constituyentes del organismo -las funciones de patrullaje- sino que también sistemas o mecanismos que fundan o determinan la aptitud del organismo para competir con otros, esto es, para su crecimiento y su reproducción. La consideración más detenida de estas propuestas de Pradeu y Clarke servirá para precisar una perspectiva en la que luego se podrán integrar las ideas centrales de la propuesta de Wilson.

Principia 21(1): 13-40 (2017). 


\subsection{Inmunidad}

Para Thomas Pradeu, en primer lugar, un organismo es un "todo funcionalmente integrado, compuesto por componentes heterogéneos que están localmente conectados por interacciones bioquímicas fuertes y controlados por interacciones inmunes que son sistémicas y constantes" (2012, p.258). Lo que interesa aquí es precisar cuáles sean las condiciones de identidad de un organismo entendido de este modo. Si un organismo es esencialmente un 'todo funcionalmente integrado', entonces uno estaría inclinado a pensar que la identidad de un organismo en el tiempo está constituida por la identidad del mismo 'todo'. Esta propuesta, sin embargo, no parece muy promisoria. Un 'todo', al menos cuando se lo entiende como una 'suma mereológica', ${ }^{4}$ depende ontológicamente de sus partes que determinan, por lo tanto, sus condiciones de identidad. Si las partes del 'todo' son las mismas, el 'todo' es el mismo. Si las partes del 'todo' son diferentes, entonces se trata de 'todos' diferentes. Lo que típicamente se encuentra en un organismo biológico, sin embargo, es que las partes que lo constituyen varían permanentemente - o podrían ser diferentes de cómo son. Es más, el organismo puede continuar existiendo en el tiempo, precisamente porque es capaz de absorber entidades que no son 'partes de sí' y hacerlas 'partes de sí', así como es capaz de excretar 'partes de sí' y hacer que dejen de ser 'partes de sí'. Es un signo de la muerte de un organismo que este proceso de renovación se detenga, como cuando un animal deja de respirar. No tendría ningún sentido, por lo tanto, pretender que la identidad del mismo 'todo', sea o no 'funcionalmente integrado', sea aquello que determine las condiciones de identidad de un organismo. El hecho de que las partes en cuestión sean heterogéneas y estén conectadas por interacciones bioquímicas fuertes no tiene tampoco ninguna importancia, por las mismas razones.

Pradeu también indica que un organismo es un todo funcionalmente integrado que está 'controlado' por interacciones inmunes que son sistemáticas y constantes. Se ha indicado ya la importancia que Pradeu le asigna a este 'control' por las interacciones inmunes para la constitución del organismo. Lo que efectúan estas interacciones inmunes es la persistencia del organismo siendo idéntico en diferentes tiempos. La idea central es que las condiciones de identidad en el tiempo de un organismo está fundada en la acción del mismo organismo. De un modo más preciso, las condiciones de identidad de un organismo biológico podrían ser formuladas de este modo, de acuerdo a la teoría de Pradeu:

Identidad de organismos I $\square \forall x \forall y \square[(x=y) \leftrightarrow(x$ ha sido causado por la acción del sistema inmunológico de $y$ ).

En este principio de Identidad de organismos I las variables ' $x$ ' e ' $y$ ' tienen como rango organismos biológicos en un tiempo. El principio, por lo tanto, no es un principio que determina en qué consiste que algo sea un organismo biológico, sino 
simplemente un principio que permite — por decirlo de algún modo- 'conectar' los organismos entre sí en diferentes tiempos. Si un organismo $O_{1}$ en el tiempo $t_{1}$ existe debido a interacciones del sistema inmunológico del organismo $\mathrm{O}_{2}$ en el tiempo $t_{2}$, entonces $O_{1}-$ en $-t_{1}=O_{2}-$ en $-t_{2}$. Y, al revés, si el organismo $O_{1}-$ en $-t_{1}=O_{2}-$ en $-t_{2}$, entonces debe existir una conexión causal entre las interacciones del sistema inmunológico de uno de esos organismos y el otro. Puede parecer aquí demasiado fuerte la existencia de una conexión 'causal' entre estos organismos. Normalmente, se supone que si el evento $e_{1}$ causa el evento $e_{2}$, entonces, si $e_{1}$ hubiese acaecido, $e_{2}$ también hubiese acaecido, y si $e_{1}$ no hubiese acaecido, entonces $e_{2}$ no hubiese acaecido. El evento causa no sólo se supone necesario - si es que las condiciones no son muy diferentes respecto de cómo son actualmente- sino que también se supone que es suficiente para la ocurrencia del efecto - nuevamente, si es que las condiciones no son muy diferentes respecto de cómo son actualmente. Pero parece muy poco verosímil pensar que todos los estados de cosas que conforman a un organismo en un tiempo hayan de haber sido causados en este sentido por la operación del sistema inmunológico en un tiempo anterior. Por estos motivos, cuando se sostiene en el principio de Identidad de organismos I que un organismo ha de ser 'causado' por la acción del sistema inmunológico de un organismo, sólo se está enunciando que el 'estado de cosas total' en que está fundado un organismo en un tiempo no existiría sin la operación del sistema inmunológico en un tiempo anterior. Pero las interacciones inmunológicas no son por sí mismas suficientes para cada aspecto de un organismo en un tiempo, aunque son - por lo menos — necesarias para que el organismo tenga el estado que tiene.

Puede resultar también aquí extraño hablar de un organismo fundado en un "estado de cosas total". Un organismo parece ser un objeto, y un objeto es un constituyente de un estado de cosas y no un estado de cosas. Se funda aquí un organismo en un estado de cosas pues un organismo en un tiempo ha de estar fundado, tal como se ha indicado ya, en una agrupación de objetos heterogéneos entre sí conectados por diferentes interacciones. La suma de dos estados de cosas cuenta también como un estado de cosas. Cualesquiera sean los objetos —átomos, moléculas orgánicas, etc.- que constituyan un organismo en un tiempo y cualesquiera sean las relaciones requeridas entre tales objetos para constituir un organismo, el organismo en cuestión habrá de estar fundado en la fusión mereológica de todos los estados de cosas de estar esos objetos en tales relaciones entre sí. De este modo también se podrá entender por qué en el principio de Identidad de organismos I los organismos aparezcan como relata de la relación causal. Son relata de conexiones causales porque hay estados de cosas que los fundan que son relata de la conexión causal.

También podría llamar la atención aquí que la relación de ser causado por la acción del sistema inmunológico de no es una relación simétrica. La causalidad es asimétrica. Se ha explicado, sin embargo, que cualquier relación que pretenda determinar 
las condiciones de identidad debe ser una relación de equivalencia reflexiva, simétrica y transitiva, tal como lo es la identidad. Esto puede ser reparado sin grandes dificultades, sin embargo. Sea la relación de ser causado por la acción del sistema inmunológico de designada por "Inm". Si hay relaciones $R$ y $S$, entonces también existe la relación $[R \vee S$ ] en la que están dos objetos si y sólo si, están en la relación $R$ o están en la relación $S$. De acuerdo al principio de Identidad de organismos $I$ para dos organismos $O_{1}-$ en $-t_{1}$ y $O_{2}-$ en $-t_{2}$, $\left[O_{1}-\right.$ en $-t_{1}=O_{2}-$ en $\left.-t_{2}\right]$ si y sólo si $\operatorname{Inm}\left(O_{1}-\right.$ en $-t_{1}, O_{2}-$ en $\left.-t_{2}\right)$. Sea $\operatorname{Inm}^{+}(x, y)$ la conversa de $\operatorname{Inm}(x, y)$, esto es, la relación de causar mediante la acción del propio sistema inmunológico. Sea, ahora, $\left[\operatorname{Inm}^{*}(x, y)=_{d f}\left(\operatorname{Inm}(x, y) \vee \operatorname{Inm}^{+}(y, x)\right)\right]$. Es claro que aunque Inm no es simétrica, Inm* sí lo es. El principio de Identidad de organismos I puede ser formulado — con las mismas prevenciones indicadas arriba- como:

Identidad de organismos I $\square \forall x \forall y \square\left[(x=y) \leftrightarrow \operatorname{Inm}^{*}(x, y)\right]$

Se requiere también que la relación de equivalencia sea reflexiva, pero la causalidad no lo es. La relación Inm ó Inm* no parece adecuada, por lo tanto, para fijar las condiciones de identidad en el tiempo de un organismo. Contra las apariencias, sin embargo, la relación Inm ó Inm* sí es reflexiva. En efecto, la relación Inm* se da entre el mismo organismo, pero para que se dé se requiere que exista una relación causal entre el sistema inmunológico del organismo en un tiempo con estados de cosas constituyentes del organismo en otro tiempo. Los estados de cosas, que son los relata de la conexión causal, son diferentes, pero el objeto de que se trata es el mismo. Es decir, la relación Inm* está fundada en conexiones causales entre estados de cosas. Tales estados de cosas, por su parte, fundan parcialmente los organismos en esos tiempos. ${ }^{5}$

\subsection{Patrullaje y demarcación}

Cuando se considera la perspectiva de Clarke las condiciones de identidad también parecen tener que ver con la acción que realiza el organismo en sí mismo. Clarke sostiene que algo es un organismo "sólo si posee mecanismos que le proporcionan las propiedades necesarias para participar en un proceso de selección, esto es, la capacidad de variación heredable de aptitud" (2013, p.430). Estas propiedades tienen que ver, por un lado, con el 'patrullaje' que impide la competencia de las partes de un organismo entre sí y con la 'demarcación' que habilita la competencia del organismo con otros organismos. Las interacciones inmunológicas son una forma de 'patrullaje', pero también lo son la división de labores reproductivas respecto de las restantes labores del organismo o la existencia de un 'cuello de botella' en el inicio del ciclo vital de un organismo. Las funciones de demarcación también se realizan en las interacciones inmunológicas por las que un organismo establece un límite entre lo que es

Principia 21(1): 13-40 (2017). 
parte del organismo y lo que no lo es. Cualquiera de estas funciones, sin embargo, ha de consistir en acciones del organismo sobre sí mismo. La diferencia entre Pradeu y Clarke es que en vez de limitar la acción del organismo relevante para la identidad en el tiempo a la del sistema inmunológico, ésta se extiende a dos 'acciones funcionales' que admiten ser 'realizadas' de una pluralidad de modos. Estas son las acciones de los sistemas de 'patrullaje' y ‘demarcación', cualquiera sean éstas. De manera abreviada, la relación de ser causado por la acción del sistema de patrullaje o de demarcación de será designada por "PatDem". Se pueden formular, entonces, las condiciones de identidad de organismos como:

Identidad de organismos II $\square \forall x \forall y \square[(x=y) \leftrightarrow \operatorname{PatDem}(x, y)]$

Las variables ' $x$ ' e ' $y$ ' tienen como rango organismos. Valen aquí las mismas prevenciones que para la relación Inm. No es simétrica, pero sí es reflexiva. Para generar una relación simétrica se define:

$$
\left.\operatorname{PatDem}^{*}(x, y)=_{d f}\left(\operatorname{PatDem}(x, y) \vee \operatorname{PatDem}^{+}(y, x)\right)\right],
$$

en donde PatDem ${ }^{+}$es la conversa de PatDem. Esta relación PatDem* sí es simétrica. Se puede formular el principio de Identidad de organismos II de este modo:

Identidad de organismos II $\square \forall x \forall y \square\left[(x=y) \leftrightarrow \operatorname{PatDem}^{*}(x, y)\right]$

Se ve que ésta es una generalización de las interacciones inmunológicas a las que hace mención Pradeu. La cuestión que queda ahora por considerar es si es posible acomodar también la concepción tripartita de Wilson al modelo de estas especificaciones de condiciones de identidad.

\subsection{Agentes vivientes}

De acuerdo a Robert Wilson, algo es un organismo si satisface tres condiciones: (i) se trata de un agente viviente, (ii) que pertenece a un linaje reproductivo, y (iii) con autonomía funcional mínima (cf. Wilson 2005, p.59). Un agente viviente, por otra parte, es: (i.a) algo con partes heterogéneas y especializadas, (i.b) que crece, se desarrolla, se reproduce y se repara, y (i.c) que tiene un metabolismo y se adapta a su ambiente (cf. Wilson 2005, pp.56-7). Es menos notorio en la teoría tripartita de Wilson el tipo de acción sobre sí que tiene un puesto preponderante en las teorías de Pradeu y Clarke, pero — tal como se mostrará— también está aquí presente.

No tendría mucho sentido considerar la pertenencia a un linaje reproductivo y la autonomía funcional mínima como constitutivos de las condiciones de identidad de un organismo. Se trata, más bien, de requerimientos impuestos para diferenciar a los organismos del resto de las entidades biológicas que forman parte de la categoría más general de 'agente viviente'. La pertenencia al mismo linaje reproductivo 
es claramente insuficiente para la identidad de un organismo, pues padres e hijos pertenecen al mismo linaje. Si se tratase de la pertenencia a la misma 'generación' de un linaje reproductivo, entonces sucede que los hermanos de un mismo padre son de la misma 'generación'. La 'autonomía funcional mínima' también es inadecuada para fijar condiciones de identidad de organismos, pues ni siquiera tiene sentido contar 'autonomías'. La 'autonomía' de un sistema es una atribución de éste para desarrollar sus funciones sin el auxilio de entidades externas a él. Uno podría —en un sentido derivativo- contar 'autonomías' contando los sistemas a los que se atribuye, pero no parece tener sentido decir que organismos en diferentes tiempos, por ejemplo, compartan la 'misma autonomía'.

Si se van a postular condiciones de identidad para organismos en el tiempo que estén basadas en la teoría tripartita de Wilson, deberá atenderse al requerimiento de tratarse de un 'agente viviente', por lo tanto. La idea general tendría que ser que el organismo $O_{1}-$ en $-t_{1}$ es idéntico al organismo $O_{2}-$ en $-t_{2}$ si y sólo si $O_{1}$ y $O_{2}$ son el mismo agente viviente. De acuerdo a Wilson, tal como se ha indicado, algo es un agente viviente si es que posee partes heterogéneas que cumplen funciones especializadas y si es capaz de desarrollar una serie de funciones, tales como metabolizar, crecer, reproducirse y repararse. Ya se ha indicado, sin embargo, que es característico de un organismo el variar cuáles sean sus 'partes' en el tiempo. No podría, por esto, sostenerse que la identidad de un organismo en el tiempo sea fijada por la posesión de las mismas 'partes'. Lo que resta, sin embargo, son las funciones de metabolizar, crecer y repararse. La reproducción es una acción que, por definición, tiene por objeto la constitución de un organismo diferente de sí por lo que tampoco debería entrar en las condiciones de identidad. Si se atiende, ahora, a las funciones de metabolizar, crecer y repararse, resulta nuevamente que se trata de acciones del organismo que versan sobre sí mismo. Son acciones que preservan la identidad en el tiempo del organismo al hacer que el mismo organismo exista en otros tiempos. Se puede apreciar ahora que la teoría tripartita de Wilson parece fundar una especificación de condiciones de identidad para organismos en el tiempo de acuerdo a la cual el organismo $O_{1}-$ en $-t_{1}$ es idéntico al organismo $O_{2}-$ en $-t_{2}$, si y sólo si el organismo $O_{2}$ ha sido causado por la acción de metabolizar, crecer o repararse de $O_{1}$. Lo que sigue ahora será ya familiar. Sea la relación de haber sido causado por la acción de metabolizar, crecer o repararse de designada por 'MCR'. Entonces, se podría formular el siguiente principio de identidad:

\section{Identidad de organismos III $\square \forall x \forall y \square[(x=y) \longleftrightarrow \operatorname{MCR}(x, y)]$}

Las variables tienen como rango organismos. La relación MCR es una relación reflexiva por los motivos ya explicados. Para generar una relación simétrica se define $\left[\mathbf{M C R} *(x, y)=_{d f}\left(\operatorname{MCR}(x, y) \vee \mathbf{M C R}^{+}(y, x)\right)\right] . \mathbf{M C R}^{+}$es la conversa de $\mathbf{M C R}$. Entonces: 
Identidad de organismos III $\square \forall x \forall y \square\left[(x=y) \longleftrightarrow \mathbf{M C R}^{*}(x, y)\right]$

Se puede apreciar, por lo tanto, que hay una coincidencia muy notoria entre las posiciones de Pradeu, Clarke y Wilson, la que se hace especialmente clara cuando se consideran las condiciones de identidad en el tiempo que deberían ser propuestas para organismos de acuerdo a estas concepciones de un organismo biológico.

\subsection{Un punto de vista unificado}

Al constatar las importantes coincidencias entre las concepciones de Pradeu, Clarke y Wilson parece razonable postular un punto de vista unificado acerca de las condiciones de identidad de organismos en el tiempo. Tal como se ha visto, lo que parece diferenciar estas posiciones no es la idea central de que la identidad en el tiempo de un organismo está fundada en la acción que el organismo realiza sobre sí mismo, sino simplemente en la caracterización de tal acción. Para Wilson se trata de las actividades por las que un organismo recaba energía del medio ambiente y construye o re-construye sus propias estructuras. Para Pradeu se trata de las actividades del sistema inmunológico por las que se controlan los crecimientos desordenados al interior del organismo y se establecen los límites de lo que es 'interno' o 'externo' al organismo. Para Clarke se trata de cualquier mecanismo que permite satisfacer las funciones de 'patrullaje' y de 'demarcación', esto es, cualquier mecanismo que permita controlar la competencia entre las partes del organismo o que habilite al organismo para participar de un proceso selectivo. Parece natural aquí pensar que todas estas actividades pueden ser unificadas como actividades cuyo objeto es la identidad del organismo en el tiempo. En cada tiempo, el organismo está fundado en las moléculas orgánicas que lo constituyan y las relaciones que éstas posean entre sí. ${ }^{6}$ La actividad del organismo, ya sea para asegurar la asimilación de los nutrientes requeridos para la conformación de las estructuras del organismo, o ya sea para asegurar la energía requerida para proseguir su actividad es actividad dirigida a asegurar la existencia del mismo organismo en el futuro. La actividad inmunológica, tal como la actividad que pueda caer bajo la categoría general de 'patrullaje' puede verse como dirigida al mismo objetivo. Se trata de actividad que limita los desarrollos que puedan amenazar la persistencia en el tiempo del organismo, que determinan la frontera entre el organismo y su ambiente. Tal vez lo que menos se preste para esta unificación sea la actividad bajo la categoría general de 'demarcación', de acuerdo a Clarke. Este tipo de actividad está dirigida a la reproducción del organismo y a maximizar la variedad heredable en los nuevos organismos. Como la reproducción no es actividad dirigida a la preservación de la propia identidad, sino a la generación de otro organismo, puede dejarse a un lado.

Se puede, entonces, proponer un principio de identidad para organismos del siguiente tenor:

Principia 21(1): 13-40 (2017). 
Identidad de organismos IV $\square \forall x \forall y \square[(x=y) \leftrightarrow(x$ ha sido causado por la actividad de auto-preservación de $y)]$

Si la relación de haber sido causado por la actividad de auto-preservación de se designa como 'Auto', entonces se puede definir la relación simétrica [Auto* $(x, y)=_{d f}$ (Auto $\left.\left.(x, y) \vee_{\text {Auto }}(y, x)\right)\right]$. Auto $^{+}$es la conversa de Auto. Por lo tanto, el principio de Identidad de organismos IV admite ser formulado como:

\section{Identidad de organismos IV $\square \forall x \forall y \square\left[(x=y) \longleftrightarrow \operatorname{Auto}^{*}(x, y)\right]$}

Esta concepción concuerda con lo que ya había sido planteado por Pablo RazetoBarry (2012): la actividad característica de un organismo vivo es la actividad para preservar o asegurar su identidad en el tiempo. ${ }^{7}$ Ya se ha explicado más arriba que la relación Auto es una relación reflexiva, pero no implica auto-causación. Hay causación entre cierto estado de cosas o ciertos estados de cosas que fundan - al menos, parcialmente- el organismo en un tiempo $t_{1}$ y los estados de cosas que fundan -al menos, parcialmente- al organismo en un tiempo posterior $t_{2}$. Los estados de cosas causa y efecto son diferentes entre sí. Los organismos fundados en tales estados de cosas, sin embargo, son idénticos. Es por esto que la actividad de que se trata en la relación Auto es actividad que causa la identidad de un organismo en diferentes tiempos o, en otras palabras, es actividad que causa la persistencia en el tiempo del mismo organismo.

Condiciones de identidad de este tenor pueden parecer impredicativas. En efecto, lo que funda la identidad de dos organismos $O_{1}-$ en $-t_{1}$ y $O_{2}-$ en $-t_{2}$ es el hecho de que $O_{2}-$ en $-t_{2}$ ha sido causado por la actividad de auto-preservación de $O_{1}-$ en $-t_{1}$, pero algo cuenta como 'actividad de auto-preservación' si es que es actividad dirigida a mantener la identidad en el tiempo. De este modo, la identidad de $O_{1}-\mathrm{en}-t_{1}$ y $\mathrm{O}_{2}-$ en $-t_{2}$ estaría fundada en el hecho de que $\mathrm{O}_{2}-$ en $-t_{2}$ ha sido causado por la actividad de 'mantener su identidad en el tiempo' de $O_{1}-$ en $-t_{1}$. ¿No es esto una forma alambicada de decir que la identidad de los organismos en el tiempo está fundada en la identidad de los organismos en el tiempo? No, no lo es. La actividad de auto-preservación de un organismo $O$ no es actividad de auto-preservación porque —de hecho- haya sido exitosa en mantener la identidad en el tiempo de $O$. Es actividad dirigida a la preservación de la identidad, sea o no sea exitosa en alcanzar la persistencia en el tiempo. Hay fracaso cuando, por ejemplo, el organismo $O$ muere en un tiempo $t_{n}$. La actividad de auto-preservación de $O$ en el tiempo $t_{n-1}$ no fue adecuada para hacer que $O$ existiese en $t_{n}$, pero esto no hace que la actividad de $O$ en $t_{n-1}$ no haya sido de auto-preservación. Lo que funda la identidad de organismos en el tiempo es el hecho de que se pueden conectar causalmente tales organismos por actividad de auto-preservación. ${ }^{8}$

También podría parecer que condiciones de identidad tales como las enunciadas por el principio de Identidad de organismos IV presupone la identidad en el tiempo 
de los organismos en vez de fundarla. ${ }^{9}$ En efecto, cualquier actividad que desarrolle un organismo debe tomar algún lapso de tiempo, por pequeño que este sea. No podrían conectarse los organismos $O_{1}-\mathrm{en}-t_{1}$ con el organismo $O_{2}-\mathrm{en}-t_{2}$ si $O_{1}$ no pudiese desplegar actividad temporalmente distendida en la que, por hipótesis, $O_{1}$ debe persistir siendo el mismo organismo durante todo ese lapso. Así, se requiere previamente la identidad en el tiempo de $O_{1}$ para que puedan funcionar las condiciones de identidad estipuladas. Pero el principio de Identidad de organismos $I V$ no requiere que los organismos que están siendo conectados por la actividad de autopreservación sean ambos temporalmente instantáneos. Lo único que se requiere es que el organismo causado por la actividad de auto-preservación sea temporalmente instantáneo. El organismo temporalmente anterior puede estar temporalmente distendido -lo que es razonable dado que ha desplegado actividad de auto-preservación. ¿Cómo es que el organismo causante de la actividad de auto-preservación es idéntico en distintos tiempos? Se debe aplicar el mismo principio de Identidad de organismos IV nuevamente de manera recursiva. El organismo temporalmente instantáneo en el último instante de ese lapso debe ser causado por la actividad de auto-preservación del organismo temporalmente anterior. Etcétera.

Hasta este momento se ha hablado casi exclusivamente de las condiciones de identidad en el tiempo y no se ha tratado acerca de las condiciones de identidad entre diferentes mundos posibles. El mismo principio de Identidad de organismos $\mathrm{IV}$ permite fijar tales condiciones de identidad. Sea un organismo $O_{1}$ en un mundo posible $w_{1}$ y un organismo $\mathrm{O}_{2}$ en un mundo posible $w_{2}$. En cada uno de esos mundos posibles los organismos en cuestión tienen una trayectoria en el tiempo - por lo que hay hechos acerca de cómo es que tales organismos persisten. Se puede postular aquí, de un modo análogo como para el caso temporal que $O_{1}-\mathrm{en}-w_{1}=O_{2}-\mathrm{en}-w_{2}$ si y sólo si Auto* $\left(\mathrm{O}_{1}-\mathrm{en}-w_{1}, \mathrm{O}_{2}-\mathrm{en}-w_{2}\right)$, esto es, si es que $\mathrm{O} 1$ hubiese sido causado por la actividad de auto-preservación de $\mathrm{O}_{2}$, o $\mathrm{O}_{2}$ hubiese causado $\mathrm{O}_{1}$ por su actividad de auto-preservación. Por ejemplo, $\mathrm{O}_{2}-\mathrm{en}-w_{2}$ podría haber sido causado por la actividad de auto-preservación de $O_{1}-$ en $-w_{1}$ si es que el estado de cosas 'total' que funda a $O_{1}$ en algún tiempo de existencia de $O_{1}$ hubiese podido causar el estado de cosas 'total' que funda el organismo $O_{2}$. En el mundo posible $w_{1}$ nunca $O_{1}$ llega a causar tal estado de cosas 'total', pero el hecho de que podría haberlo causado hace que sea una posibilidad para $\mathrm{O}_{1}$ ser del modo en que lo es $\mathrm{O}_{2}$. El mismo principio de Identidad de organismos $I V$ permite fijar la identidad entre diferentes mundos posibles.

\subsection{Una objeción}

Ereshevsky y Pedroso (2015) han hecho notar la importancia sistemática que puede tener para la filosofía de la biología el caso de los biofilms. Los biofilms son colonias de micro-organismos — de la misma o de diferentes especies- conectados por estruc- 
turas que los protegen, que facilitan su alimentación, que permiten su comunicación por señales químicas y la transferencia genética lateral entre ellos. Los biofilms presentan algo que podría ser calificado como un 'ciclo vital'. Se forman por la llegada a un hábitat de micro-organismos aislados. La llegada de otros, de la misma o de otras especies, permite el desarrollo del biofilm mediante la generación de una sustancia extra-celular que conecta a los micro-organismos entre sí. En algún sentido, también, el biofilm puede luego 'reproducirse', pues al llegar a su 'madurez' desprende células que se dispersan y pueden dar lugar a otro biofilm (cf. para estos detalles, Ereshevsky y Pedroso 2015, pp.104-6). Hay formas de 'agencia' que podrían ser atribuidos a los biofilms, pero no hay intuiciones claras acerca de si se trata de una forma de organismo, una colonia con niveles altos de cooperación entre sus miembros o un ecosistema. Son, por estos motivos, un buen campo para contrastar teorías generales que podrían estar sobre-simplificando en el afán de universalidad.

El problema —o el aparente problema, si se quiere- para el tipo de posición propuesta aquí acerca de las condiciones de identidad de los organismos es que en el caso de los biofilms parecen presentarse casos en los que, por ejemplo, la función de patrullaje es realizada por factores ambientales externos al biofilm de que se trata. No parece en estos casos, por lo tanto, que pueda sostenerse que la existencia del mismo organismo en diferentes tiempos pueda ser causada por el organismo actuando sobre sí mismo. Un ejemplo considerado por Ereshefsky y Pedroso (cf. 2015, pp.114-5) es el de la bacteria Pseudomonas fluorescens. Esta bacteria se da en dos cepas. Una de estas cepas produce un polímero de celulosa que permite el desarrollo de un biofilm en superficies líquidas. Al desarrollarse el biofilm se puede alojar, sin embargo, otra cepa de la bacteria Pseudomonas fluorescens que no produce tal polímero y que se aprovecha de las ventajas comunes que han contribuido las restantes. Un biofilm con alta prevalencia de la cepa 'colaborativa' de la Pseudomonas fluorescens se desarrollará y llegará a su madurez con más probabilidad que un biofilm con alta prevalencia de la cepa 'oportunista'. Se ha hallado que la frecuencia de perturbaciones ecológicas a la que se vea sometido un biofilm puede determinar la prevalencia de bacterias 'cooperativas' o 'oportunistas'. Si hay perturbaciones muy frecuentes no resulta ventajosa la formación de un biofilm. Lo interesante es que si las perturbaciones ecológicas son infrecuentes, aumenta la prevalencia de las bacterias de la cepa 'oportunista'. La existencia de perturbaciones más frecuentes, pero moderadas, en cambio, favorece la prevalencia de la cepa 'colaborativa' y, con ello, la generación del polímero de celulosa necesario para el desarrollo del biofilm. Así, son factores ambientales externos al biofilm los que parecen operar como mecanismos de 'patrullaje' para limitar el crecimiento desordenado de colonias de bacterias poco beneficiosas.

Debe decirse a propósito de este supuesto contra-ejemplo que un biofilm parece ser un individuo biológico, pero es controversial que pueda ser aceptado como un 
'organismo'. ${ }^{10}$ Ninguna de las teorías explicadas acerca de la naturaleza de un organismo permite arribar a un veredicto claro acerca de si se trata de un ecosistema o de un organismo. Esto hace que, de entrada, el valor que puedan tener casos como éste para evaluar las condiciones de identidad propuestas es limitado. Aún aceptando que los biofilms sean organismos, sin embargo, puede apreciarse que casos como el indicado no constituyen contra-ejemplos a las condiciones de identidad especificadas. En efecto, un contra-ejemplo al principio de Identidad de organismos $I V$ sería o bien (i) un caso en donde exista identidad de dos organismos pero no exista actividad de auto-preservación que los conecte, o bien (ii) un caso en donde exista actividad de auto-preservación conectando dos organismos, pero sin que exista identidad entre ellos. El caso de los biofilms conformados por la Pseudomonas fluorescens tendría que ser del tipo (i), esto es, un caso en el que el mismo organismo persiste en el tiempo, pero la persistencia no es causada por la actividad de auto-preservación. Se supone que en el caso tratado, la persistencia del biofilm en el tiempo es provocada por la frecuencia de perturbaciones ecológicas a las que el biofilm se vea expuesto. Pero es claro que un caso así no contaría realmente como una situación en la que la persistencia en el tiempo no sea causada por la actividad de auto-preservación del organismo. Uno de los muchos factores relevantes para la persistencia en el tiempo de un biofilm es el control de las bacterias no cooperativas, pero no es de ningún modo el único. La persistencia del biofilm dependerá causalmente de la actividad de las bacterias que sí son cooperativas, de su comunicación mutua, de la defensa que les preste la estructura común, del metabolismo que hagan esas bacterias de los nutrientes, etc. Cada una de estas actividades cuenta como actividad de auto-preservación. Tal como se ha indicado más arriba, cuando se ha sostenido que la persistencia en el tiempo ha sido causada por la actividad del mismo organismo, no se pretende decir que todas y cada uno de los estados de cosas que fundan a un organismo en un tiempo deben haber sido causadas por tal actividad. Sólo se sostiene que el estado total del organismo no podría existir sin tal actividad. Y esto es obviamente compatible con la incidencia causal de factores externos. Por ejemplo, cualquier organismo persiste en el tiempo, entre otras cosas, porque hay nutrientes suficientes en su ambiente. La existencia de nutrientes en la vecindad es un factor ambiental externo al organismo. Si hay nutrientes el organismo se va a desarrollar. Si no los hay, el organismo no lo hará. Esto difícilmente, sin embargo, hace que la persistencia del organismo en el tiempo no dependa causalmente de su propia actividad de auto-preservación.

Sucede, por lo demás, que no podría tampoco sostenerse que la frecuencia de perturbaciones ecológicas sea un 'mecanismo de patrullaje' del organismo. La recurrencia de las estaciones, por ejemplo, es un factor ambiental fundamental para el crecimiento de las plantas, pero esto no hace que el sistema solar cuente como un 'mecanismo de demarcación' de estas. Un 'mecanismo' relevante para la persistencia en el tiempo de un organismo — sea de 'patrullaje' o no- es algo a lo que debe po- 
der atribuirse tal 'función'. Por supuesto, ha existido una enorme controversia acerca de cómo deba ser comprendida la naturaleza de una 'función' en Biología, especialmente si se las pretende reducir a una perspectiva general naturalista (cf. para un panorama general, Garson, 2016). Bajo ninguna de las alternativas que han sido discutidas para comprender una 'función biológica', sin embargo, pareciera que la frecuencia de perturbaciones ecológicas pueda contar como un 'mecanismo' dotado de una 'función'. En primer lugar, no parece razonable pensar que la frecuencia de las perturbaciones ecológicas tenga como 'finalidad' impedir el desarrollo de colonias de la cepa 'oportunista' de la Pseudomonas fluorescens. Tampoco tendría sentido sostener que la frecuencia de las perturbaciones ecológicas sea un rasgo heredable de los biofilms de Pseudomonas fluorescens que históricamente ha mejorado la aptitud para la supervivencia de estos biofilms. Así, casos como el presentado no constituyen contra-ejemplos a las condiciones de identidad para organismos aquí propuestas.

\section{Conclusiones}

En este trabajo se han presentado tres teorías diferentes acerca de la naturaleza de los organismos biológicos. Robert Wilson ha sostenido que un organismo es un agente viviente que pertenece a un linaje reproductivo y que posee autonomía funcional mínima. Thomas Pradeu ha sostenido que un organismo es un todo funcionalmente integrado de partes heterogéneas controlado por interacciones inmunes. Ellen Clarke, por último, ha sostenido que un organismo es un todo funcionalmente integrado de partes heterogéneas controlado por mecanismos de patrullaje y mecanismos de demarcación. La consideración de estas tres concepciones diferentes de un organismo ha mostrado que hay coincidencias sustantivas entre ellas. Estas coincidencias son las que han sido aquí explotadas para una perspectiva unificada acerca de las condiciones de identidad de un organismo en el tiempo. En efecto, en estos tres casos, la identidad de un organismo en el tiempo depende de la actividad de este mismo organismo para su auto-preservación. Esta idea es especialmente notoria en el caso de Pradeu, pero está también operando en las propuestas de Clarke y de Wilson.

Las condiciones de identidad de un organismo quedan fijadas, entonces, por lo enunciado en el principio de Identidad de organismos $I V$ de acuerdo al cual los organismos $x$ e $y$ son idénticos si y sólo si $x$ ha sido causado por la actividad de autopreservación de $y$. Este mismo principio permite fijar las condiciones de identidad de organismos en el tiempo y en diferentes mundos posibles.

\section{Agradecimientos}

Este trabajo ha sido redactado en ejecución del proyecto de investigación VRI $N^{o} 2742-013$ de 2015 de la Pontificia Universidad Católica de Chile. Agradecemos la amabilidad de Mark 
Ereshefsky para resolver algunas de nuestras dudas acerca de su trabajo. Una versión preliminar fue presentada en el Instituto de Filosofía y Ciencias de la Complejidad (IFICC) y en el Grupo de Trabajo de Filosofía Analítica UC. Agradecemos los comentarios y las sugerencias de los asistentes a esos encuentros. Agradecemos también las observaciones a esa primera versión de Julio Torres, Davide Vecchi, Pablo Razetto y Roberto Torretti.

\section{Referencias}

Boyd, R. 1999. Homeostasis, Species, and Higher Taxa. In: R. Wilson (Ed.) Species: New interdisciplinary Essays, pp.141-185. Cambridge: MIT Press.

Buss, L. 1987. The Evolution of Individuality. New Jersey, Princeton University Press.

Clarke, E. 2010. The Problem of Biological Individuality. Biological Theory 5: 312-325.

- 2013. The Multiple Realizability of Biological Individuals. The Journal of Philosophy 110: 413-435.

— 2016. Levels of Selection in Biofilms: Multispecies Biofilms Are Not Evolutionary Individuals. Biology \& Philosophy 31(2): 191-212.

Clarke, E; Okasha, S. 2013. Species and Organisms: What Are the Problems?. In: F. Bouchard; P. Huneman (Eds.) From Groups to Individuals. Evolution and Emerging Individuality, pp.37-55. Cambridge: MIT Press.

Ereshefsky, M.; Pedroso, M. 2013. Biological Individuality: The Case of Biofilms. Biology \& Philosophy 28: 331-349.

- 2015. What Biofilms Can Teach Us About Individuality. In: A. Guay; T. Pradeu (Eds.) Individuals Across the Sciences, pp.103-119. Oxford: Oxford University Press.

Frédéric, B.; Huneman, P. (Ed.) 2013. From Groups to Individuals. Evolution and Emerging Individuality. Cambridge: MIT Press.Guay, A.; Pradeu, T. (Eds.) 2015. Individuals Across the Sciences. Oxford: Oxford University Press.

Garson, E. 2016. A Critical Overview of Biological Functions. Dordrecht: Springer.

Godfrey-Smith, P. 2009. Darwinian Populations and Natural Selection. Oxford: Oxford University Press.

- 2013. Darwinian Individuals. In: F. Bouchard; P. Huneman (Eds.) From Groups to Individuals. Evolution and Emerging Individuality, pp.17-37. Cambridge: MIT Press.

Griesemer, J. 2000. The Units of Evolutionary Transition. Selection 1: 67-80.

Janzen, D. 1977. What are Dandelions and Aphids? American Naturalist 111: 586-589.

Lewis, D. 1986. On the Plurality of Worlds. Oxford: Blackwell.

Lewontin, R. 1970. The Units of Selection. Annual Review of Ecology and Systematics 1: 1-18. Locke, J. 1975[1690]. An Essay Concerning Human Understanding. Oxford: Clarendon Press. Mackie, P. 2006. How Things Might Have Been. Individuals, Kinds, and Essential Properties. Oxford: Clarendon Press.

Martin, R.; Barresi, J. (Ed.) 2003. Personal Identity. Oxford: Blackwell.

Olson, E. 1997. The Human Animal. Personal Identity Without Psychology. New York: Oxford University Press.

- 2007. What Are We? A Study in Personal Ontology. Oxford: Oxford University Press.

Pepper, J.; Herron, M. 2008. Does Biology Need an Organism Concept? Biological Reviews 83: 621-627.

Principia 21(1): 13-40 (2017). 
Perry, J. (Ed.) 2008. Personal Identity. Berkeley: University of California Press.

Pradeu, T. 2010. What is An Organism? An Immunological Answer. History and Philosophy of Life Sciences 32: 247-267.

- 2012. The Limits of the Self: Immunology and Biological Identity. New York: Oxford University Press.

Queller, D.; Strassman, J. 2009. Beyond Society: The Evolution of Organismality. Philosophical Transactions of The Royal Society B Biological Sciences 364: 3143-3155.

Razeto-Barry, P. 2012. Autopoiesis 40 Years Later: A Review and Reformulation. Origins of Life and Evolution of Biospheres 42(6): 543-567.

Shoemaker, S.; Swinburne, R. (Eds.) 1984. Personal Identity. Oxford: Blackwell.

Sider, T. 2001. Four-Dimensionalism. An Ontology of Persistence and Time. Oxford: Clarendon Press.

Snowdon, P. 2014. Persons, Animals, Ourselves. Oxford: Oxford University Press.

Sterelny, K.; Griffiths, P. 1999. Sex \& Death: An Introduction to Philosophy of Biology. California: University of Chicago Press.

Swinburne, R. 1984. Personal Identity: the Dualist Theory. In: S. Shoemaker; R. Swinburne (Eds.) Personal Identity, pp.3-66. Oxford: Blackwell.

Wilson, R. (Ed.) 1999. Species: New interdisciplinary Essays. Cambridge: MIT Press.

- 2005. Genes and the Agents of Life. Cambridge: Cambridge University Press.

José TOMÁs AlVARADo jalvaram@uc.cl

CRISTÓBAL UNWIN cmunwin@uc.cl

Instituto de Filosofía, Pontificia Universidad Católica de Chile Av. Vicuña Mackenna 4860, Macul - Santiago, 7820436

\section{Notas}

CHILE

\footnotetext{
${ }^{1}$ Se va a utilizar la expresión "mundo posible" para designar una forma en que podrían ser las cosas. No se toma aquí ninguna posición acerca de qué deba entenderse por tales 'formas'. Por de pronto, no se supone que los 'mundos posibles' deban ser entendidos como fusiones mereológicas de todos los objetos que se encuentran localizados entre sí a cierta distancia espacial o temporal.

2 En apariencia, pues, como se verá más abajo, Pradeu reconoce la importancia de las interacciones bioquímicas locales —especialmente aquellas que involucran proteínas- en la integración funcional que muestran las diversas partes del organismo (2010, p.258).

${ }^{3}$ Peter Godfrey-Smith $(2009 ; 2013)$ comparte con Clarke una cierta caracterización de la selección natural como base para la definición de algunos individuos biológicos. Para GodfreySmith, cualquier población que, en virtud de ciertas propiedades (cf. Lewontin, 1970), sea capaz de experimentar un proceso darwiniano — evolutivo- de cambio, es una población darwiniana. Cada uno de los miembros de estas poblaciones serán, respectivamente, individuos darwinianos (Godfrey-Smith 2013, p.19). Algunas de las propiedades que estos poseen influencian, en diversos grados, el modo en cómo las poblaciones que componen participan de
} 
procesos evolutivos (Godfrey-Smith 2013, p.100). La posesión gradual de aquellas propiedades permite situar a estos individuos biológicos en un diagrama continuo que va desde casos marginales, hasta casos paradigmáticos de individualidad darwiniana (Godfrey-Smith 2013, p.21). En cuanto a los organismos, Godfrey-Smith adopta una perspectiva metabólica (2013, p.25) (cf. también Queller y Strassman, 2009) que le permite distinguir casos en los que estos son individuos darwinianos, y casos en los que no. Ejemplo de estos últimos son aquellas simbiosis en las que los simbiontes no comparten trayectorias evolutivas, pese a actuar conjuntamente como un solo organismo (Godfrey-Smith 2013, p.29). Se trata, en definitiva, de un intento por recoger tipos de individualidad biológica que han surgido en el marco de la evolución por selección natural, sin que por ello sean idénticos (Godfrey-Smith 2013, p.32). ${ }^{4}$ Mereología extensional estándar es una teoría formalizada acerca de las relaciones entre todos y partes. La forma estándar en que se entienden las nociones de 'parte' y 'todo' es como se entienden en esta teoría. Una 'suma' o 'fusión' mereológica es un todo constituido por ciertas partes y cuya identidad queda determinada por cuáles sean estas partes y nada más que cuáles sean sus partes.

${ }^{5}$ Se dice de $x$ que funda parcialmente $y$ si y sólo si, $x, z_{1}, z_{2}, \ldots, z_{n}$ fundan totalmente $y$. Y si $z_{1}, z_{2}, \ldots, z_{n}$ fundan totalmente $y$, entonces se sigue que es necesario que, si $z_{1}, z_{2}, \ldots, z_{n}$ existen, entonces y debe también existir. El fundamento de una entidad y es aquello que es constitutivamente suficiente para la existencia de $y$.

${ }^{6}$ Los estados de cosas de encontrarse tales moléculas orgánicas en tales y tales relaciones pueden fusionarse mereológicamente en un estado de cosas 'total' que los contenga como partes. El organismo en un tiempo no se identifica con tal estado de cosas 'total', pero está fundado ontológicamente en él.

${ }^{7}$ Pablo Razeto-Barry ha propuesto esto como una interpretación de la conocida idea de 'autopoiesis' de Humberto Maturana y Francisco Varela. No es nada de claro, sin embargo, cómo deban entenderse las concepciones de estos autores. Por eso creemos que la especificación de las condiciones de identidad tal como se indican en el principio de Identidad de organismos $I V$ deben atribuirse a Pablo Razeto-Barry. Es él quien por primera vez ha comprendido de manera explícita la 'autopoiesis' de este modo.

${ }^{8}$ Una cuestión diferente es que no podríamos llegar a saber que un tipo de actividad es actividad de auto-preservación si no fuese porque frecuentemente tal tipo de actividad es exitosa en preservar la identidad en el tiempo. En otras palabras, en un mundo posible en el que lo más frecuente fuese que las actividades de auto-preservación fallen tendríamos graves problemas para saber si los organismos que despliegan tal actividad son, en efecto, organismos vivos. Estos son, sin embargo, problemas epistemológicos. La cuestión aquí es que, con independencia de lo que conozcamos o de cómo lo conozcamos, hay actividades de autopreservación y son tales actividades — cuando son exitosas- las que fijan las condiciones de identidad de los organismos.

${ }^{9}$ Agradecemos esta objeción a don Roberto Torretti. Este mismo problema se puede plantear respecto de los principios de Identidad de organismos I-III. La respuesta que se ofrece aquí es aplicable a cualquiera de ellos.

${ }^{10}$ En realidad, se han manifestado dudas también de que se trate de un "individuo evolucionario", esto es, de aquellos que pueden entrar en procesos de selección natural (cf. Clarke, 2016).

Principia 21(1): 13-40 (2017). 